\title{
Tiered Approach for the Evaluation of Environmental Impacts of Triclosan on Aquatic Ecosystems
}

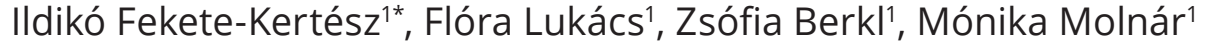 \\ ${ }^{1}$ Department of Applied Biotechnology and Food Science, Faculty of Chemical Technology and Biotechnology, \\ Budapest University of Technology and Economics, H-1111 Budapest, Szent Gellért sqr. 4., Hungary \\ * Corresponding author, e-mail: fekete.kertesz.ildiko@mail.bme.hu
}

Received: 13 July 2018, Accepted: 30 August 2018, Published online: 11 October 2018

\begin{abstract}
The synthetic broad-spectrum antibacterial agent triclosan is one of the most commonly encountered emerging micro-pollutant in the aquatic environment due to the extensive use since 1968 mainly in cosmetics and household cleaning products and the partial elimination from wastewater. Its low water solubility, high sorption coefficient to organic matter, accumulation potential in fatty tissues and its low acute toxicity determined by conventional ecotoxicological tests suggest that its risk is more related to chronic effects requiring risk assessment based on more sensitive ecotoxicological methods. In this paper the short- and midterm ecotoxicological effects of triclosan were investigated using various test systems taking into account ecological complexity and environmental relevance. Acute single-species, simplified microcosm experiments and complex multi-species microcosm experiments were conducted with the determination of sublethal physiological and behavioral endpoints including the Daphnia magna heartbeat rate and feeding activity, the Heterocypris incongruens movement parameters and the Lemna minor chlorophyll content and root length. All physiological and behavioral endpoints indicated sensitively the adverse effect of triclosan in the concentration range of 4-25.6 $\mu \mathrm{g} / \mathrm{L}$. In some cases, responses of selected organisms in single-species laboratory tests did not correspond to those of the higher levels of test systems. Daphnia sensitivity increased with the level of the test system for all chosen endpoints except the heartbeat rate. Considering the varying ecological complexity of the assembled test systems, according to our results the exposure time and the different combinations of exposure routes were the most decisive parameters in terms of triclosan ecotoxicity and endpoint sensitivity.
\end{abstract}

\section{Keywords}

ecotoxicology, triclosan, aquatic microcosm, physiological endpoints, behavioral endpoints

\section{Introduction}

The adverse effects of aquatic micro-pollutants and their fate and behavior in the environment are widely studied recently $[1,2]$. Triclosan (5-chloro-2-(2,4-dichlorophenoxy) phenol) is a synthetic broad-spectrum antibacterial agent categorized as a halogenated aromatic hydrocarbon having phenolic, diphenyl ether and polychlorinated biphenyl substructures [3]. It has been used since 1968 as an antiseptic, disinfectant, and preservative in household consumer products (cosmetics, cleaning products) and in clinical settings incorporated on the surface of medical devices [4] with an estimated annual usage of $1000 \mathrm{t}$ per year in the EU [5]. Triclosan is mainly released into the environment via the use of consumer products, which in most cases are externally applied to the human body, thus triclosan generally is not subjected to metabolic alteration [3]. Due to the partial elimination of triclosan in wastewater treatment plants, it is reported to be one of the most commonly encountered emerging micro-pollutant in solid and water environmental compartments [4]. It has been detected ubiquitously in various aquatic environments such as lakes, rivers, coastal and estuarine waters, sediments, drinking water and even in living aquatic organisms [6-8] in $n g / L-\mu g / L$ concentrations $[9,10]$.

Its toxicity can be attributed to its high hydrophobicity, hence its accumulation potential in fatty tissues. In the wastewater treatment plants and on its way to the environment, triclosan undergoes various transformation processes due to artificial (chlorination) and natural phenomena (e.g. biological methylation, photooxidation) as a consequence, triclosan may be transformed into ecotoxicologically more toxic and persistent compounds, such as chlorinated phenols, biphenyl ethers, methyl triclosan and chlorinated dibenzodioxins [4]. 
Several standard aquatic toxicity studies reported about the toxic effect of triclosan to bacteria, crustaceans, fish and photosynthetic organisms, such as microalgae and higher aquatic plants with the following $\mathrm{EC}_{50}$ values: Vibrio fischeri bioluminescence inhibition at $150 \mu \mathrm{g} / \mathrm{L}$, Daphnia magna mortality at $390 \mu \mathrm{g} / \mathrm{L}$, Pimephales promelas mortality at $260 \mu \mathrm{g} / \mathrm{L}$, Scenedesmus subspicatus growth inhibition at $1.4 \mu \mathrm{g} / \mathrm{L}$ and Lemna gibba growth inhibition at $62.5 \mu \mathrm{g} / \mathrm{L}$ [11].

Today emerging health concerns of triclosan and its by-products, are related to the endocrine disruption, allergic effect, dermal irritations, altered thyroid hormone metabolism and tumor development or microbial resistance [12-14].

Due to the low acute ecotoxicity determined with conventional ecotoxicological methods and the lack of data about its chronic adverse effects on the ecosystem and human health, triclosan is not considered as a pollutant with high priority concerns unlike other emerging micro-pollutants sharing the same structure and pharmaceutical activity such as chlorinated organic compounds and endocrine disruptors. This leads to uncontrolled use of this molecule and the increase of its concentration in the aquatic and terrestrial ecosystem.

Due to its low water solubility $\left(12 \mathrm{mg} / \mathrm{L}\right.$ at $\left.25^{\circ} \mathrm{C}\right)$ and its high sorption coefficient $\left(\mathrm{K}_{\mathrm{OC}}=18408\right)$ triclosan may adsorb to the sediment in natural water matrices. However, its potential adverse effects on bottom-dwelling aquatic organisms are not well studied [3].

Its bioconcentration factor $(\mathrm{BCF}=2.7-90)$ in aquatic organisms shows clearly that the risk may be more related to chronic effect (due to bioaccumulation) than acute impact, however existing literature data shows that the ecosystems can be disturbed even at environmental concentrations after acute exposure as well [3].

Ecological effect assessment aims at evaluating or predicting the effects of a chemical compound on the structure and function of the ecosystem and these higher-level effects are usually estimated by extrapolation of single-species effect data [15]. It has been recognized that other intermediate approaches, like simple multi-species studies between standard aquatic toxicity tests and microcosm or field studies might provide valuable data for environmental risk assessment. A range of laboratory higher tier approaches have been reported that are intermediate in complexity incorporating realistic exposure scenarios into laboratory studies such as simple multi-species studies [16].

Studies of short-, mid- and long term effects of triclosan with more sensitive physiological and behavioral ecotoxicological endpoints are important for risk assessment of aquatic environments in order to explore hidden toxic effects other than the conventional lethality, immobilization or reproduction. Therefore, the aim of this study was to assess and compare the adverse effects of triclosan in single- and multi-species ecotoxicity tests with varying environmental relevance considering the following exposure routes: direct exposure, exposure via food-absorbed contaminant uptake and considering the partition of the contaminant between the water- and the artificial sediment phase. In this purpose photosynthetic and animal test organisms were selected of different trophic levels representing free-swimming and benthic bottom-dwelling species as well.

\section{Materials and methods}

\subsection{Materials}

Triclosan (CAS Number: 3380-34-5, PHR1338-1G) was purchased from Sigma-Aldrich. The use of solvents was not necessary as triclosan is water soluble in the tested concentration range. For the acute ecotoxicity tests triclosan was dissolved in distilled water $(\mathrm{pH}=6.40 ; \mathrm{EC}=9 \mu \mathrm{S})$, while for the simplified and complex microcosm studies triclosan was dissolved in natural surface water (Collection site: Lake Balaton, Alsóörs, Hungary, approx. $300 \mathrm{~m}$ from the coastline, $\mathrm{pH}=8.65, \mathrm{EC}=620 \mu \mathrm{S}$ ).

The tested concentration of triclosan in the three different test systems is summarized in Table 1 .

\subsection{Applied test organisms}

\subsubsection{Daphnia magna cultures}

A colony of Daphnia magna cultured in the laboratory was used in a series of experiments. The test animals were cultured in $5 \mathrm{~L}$ beakers in a $21.5 \pm 1{ }^{\circ} \mathrm{C}$ thermostatic chamber with 16:8 h light: dark cycle (illumination: Juwel Aquarium, Day-Lite, $15 \mathrm{~W}, 438 \mathrm{~mm}$ lamp, 560 Lumen, $6500 \mathrm{~K}$ ) and fed everyday by $2 \mathrm{~mL}$ of alga suspension of

Table 1 Tested concentration of triclosan in the three different test systems

\begin{tabular}{lccc}
\hline & \multicolumn{3}{c}{ Triclosan concentration $[\mu \mathrm{g} / \mathrm{L}]$} \\
\hline Test organism & $\begin{array}{c}\text { Acute, } \\
\text { single-species } \\
\text { ecotoxicity tests }\end{array}$ & $\begin{array}{c}\text { Simplified, } \\
\text { small volume } \\
\text { microcosm } \\
\text { experiments }\end{array}$ & $\begin{array}{c}\text { Complex, } \\
\text { multi-species } \\
\text { microcosm } \\
\text { experiments }\end{array}$ \\
$\begin{array}{l}\text { Daphnia } \\
\text { magna }\end{array}$ & $4-2,000$ & $25.6-1,000$ & $20-2,000$ \\
$\begin{array}{l}\text { Heterocypris } \\
\text { incongruens }\end{array}$ & $20-2,000$ & $25.6-1,000$ & $20-2,000$ \\
Lemna minor & $20-2,000$ & not tested & $20-2,000$ \\
\hline
\end{tabular}


$10^{9} \mathrm{cell} / \mathrm{mL}$ concentration cultivated in the laboratory containing Chlorella sorokiniana. For maintaining D. magna aged, dechlorinated tap water and OECD M7 medium were used. To check the sensitivity of the D. magna culture acute toxicity tests were performed with potassium dichromate $\left(\mathrm{K}_{2} \mathrm{Cr}_{2} \mathrm{O}_{7}\right)$ as reference toxicant at about every six-months interval. Sensitivity of D. magna culture to $\mathrm{K}_{2} \mathrm{Cr}_{2} \mathrm{O}_{7}$ ranged within the limits $\left(\mathrm{EC}_{50}, 24 \mathrm{~h}=0.6-2.1 \mathrm{mg} / \mathrm{L}\right)$ set by guideline OECD 202 [17].

\subsubsection{Heterocypris incongruens cultures}

A colony of Heterocypris incongruens cultured in the laboratory was used in a series of tests. The test animals were cultured in $500 \mathrm{~mL}$ beakers in a $21.5 \pm 1{ }^{\circ} \mathrm{C}$ thermostatic chamber with 16:8 h light: dark cycle (illumination: Juwel Aquarium, Day-Lite, 15 W, 438 mm lamp, 560 Lumen, $6500 \mathrm{~K})$ and fed everyday by an alga suspension cultivated in the laboratory containing Chlorella sorokiniana. For maintaining $H$. incongruens aged, dechlorinated tap water were used. The beakers contained $50 \mathrm{~g}$ of artificial sediment phase with the following composition: $65 \%$ sand, $30 \%$ kaolinite powder, $3.9 \%$ ground peat, $1 \%$ cellulose powder and $0.1 \% \mathrm{CaCO}_{3}$.

\subsubsection{Lemna minor cultures}

A colony of Lemna minor cultured in the laboratory was used in this experiment. The test organism was cultured in a $20 \times 30 \times 7 \mathrm{~cm}$ glass container in a $21.5 \pm 1{ }^{\circ} \mathrm{C}$ thermostatic chamber with 16:8 h light:dark cycle (illumination: Juwel Aquarium, Day-Lite, $15 \mathrm{~W}, 438 \mathrm{~mm}$ lamp, 560 Lumen, $6500 \mathrm{~K}$ ). For the maintenance Hoagland's nutrient medium was used, which was renewed twice a week. The composition of Hoagland's nutrient medium is explained in the publication of Fekete-Kertész et al. [18].

\subsection{Acute, single-species ecotoxicity tests}

\subsubsection{Daphnia magna lethality and immobilization assay}

The Daphnia magna acute lethality and immobilization tests were performed as described in the OECD 202 test protocol [17].

\subsubsection{Daphnia magna heartbeat rate assay}

For the test non-pregnant 10-day-old D. magna individuals were used, which did not derive from first brood. The animals were not fed during the test. The dissolved $\mathrm{O}_{2}$ concentration was more than $3 \mathrm{mg} / \mathrm{L}$ at the end of the test recommended by the OECD 202 Guideline [17]. 10 animals were placed into three parallels of $50 \mathrm{~mL}$ test solution in a $150 \mathrm{~mL}$ test vessel with the help of a special fabric spoon. As a control, distilled water was applied with growth medium in the same proportion as in the triclosan containing samples. The beakers were covered with a translucent plastic film to avoid evaporation and concentration of the test suspension during the experiment and incubated under the same conditions as described in Section 2.2.1. The heartbeat rate of the animal was measured twice during the test, after 24 and $48 \mathrm{~h}$ exposure times. Counting of the heartbeat rate was carried out under a stereomicroscope (NIKON SMZ800). The test animals were placed onto a single cavity microscope slide in a $50 \mu \mathrm{L}$ droplet of the test suspension, where the heartbeat rate of the test animals was measured one-byone (individually), three times for 10 seconds. Each measurement was repeated three times.

\subsubsection{Daphnia magna feeding inhibition assay}

The test was carried out based on the method of Kamaya et al. [19] with major modifications. For the test non-pregnant 10-day-old $D$. magna individuals were used, which did not derive from first brood and were starved for 3 days prior to the test and were not either fed during the test. The dissolved $\mathrm{O}_{2}$ concentration (determined with WTW "Portable Meter $\left.340 \mathrm{i}^{\prime}\right)$ was more than $3 \mathrm{mg} / \mathrm{L}$ at the end of the test recommended by the OECD 202 Guideline [17]. 10 animals were placed into two parallels of $50 \mathrm{~mL}$ test solution in a $150 \mathrm{~mL}$ glass test vessel with the help of a special fabric spoon. As a control, distilled water was applied with growth medium in the same proportion as in the triclosan containing samples. The beakers were covered with a translucent plastic film to avoid evaporation and concentration of the test suspension during the experiment and incubated under the same conditions as described in Section 2.2.1.

After $48 \mathrm{~h}$ of exposure time the ten individuals from the same test vessel were transferred into $10 \mathrm{~mL}$ of a $3 \mu \mathrm{L}$ / $\mathrm{mL}$ concentration fluorescent microsphere suspension (Life Technologies; FluoSpheres ${ }^{\mathrm{TM}}$ Carboxylate-Modified Microspheres, $0.2 \mu \mathrm{m}$, yellow-green fluorescent (505/515), $2 \%$ solids) diluted with the original D. magna growth medium. The individuals were kept in the fluorescent microsphere suspension letting them feed for $20 \mathrm{~min}$, then they were taken out with the help of a special fabric spoon, washed thoroughly with distilled water in order to remove the microspheres adhered onto their carapace and appendages and could influence the results. The washed individuals were transferred into a micro test tube in $1 \mathrm{~mL}$ of distilled water, then homogenized for $30 \mathrm{~s}$ with UP $200 \mathrm{H}$ Ultrasonic Processor (Hielscher Ultrasonics $\mathrm{GmbH}$ ) 
with the following settings: cycle: 1 , amplitude $\%$ : 82 . The homogenized Daphnia-microsphere suspensions were pipetted into three parallel wells of a 96-well microtiter plate and the fluorescence intensity of the wells was measured by FLUOstar Optima BMG Labtech microplate reader using the excitation wavelength of $485 \mathrm{~nm}$ and the emission wavelength of $520 \mathrm{~nm}$.

\subsubsection{Heterocypris incongruens lethality and immobilization assay}

For the test 10-day-old $H$. incongruens individuals were used. The animals were not fed during the test. 5 animals were placed into three parallels of $10 \mathrm{~mL}$ test solution in a $12 \mathrm{~mL}$ volume test vessel with the help of a special fabric spoon. As a control, distilled water was applied with growth medium in the same proportion as in the triclosan containing samples. The test vessels were covered with a translucent plastic film to avoid evaporation and concentration of the test suspension during the experiment and were kept under dark circumstances in a $21.5 \pm 1{ }^{\circ} \mathrm{C}$ thermostatic chamber. Lethality and immobilization were registered twice during the test, after 24 and $48 \mathrm{~h}$ exposure times. Each measurement was repeated three times.

\subsubsection{Heterocypris incongruens movement ability inhibition assay}

For the registration of the movement parameters (total distance and average velocity) the alive, non-immobile $H$. incongruens individuals were micro-pipetted individually in $1.5 \mathrm{~mL}$ of the original test medium to a $2 \mathrm{~mL}$ volume flat bottomed cylindrical test vessel.

A sequence of 100 images was taken every $50 \mathrm{~ms}$ with QImaging Micropublisher 5.0 RTV digital microscope camera connected to a NIKON SMZ800 stereomicroscope under 5-times magnification. The sequence was evaluated with Image-Pro Plus 7.0 software.

\subsubsection{Lemna minor growth inhibition assay}

On the first day 10 healthy and two-leaf L. minor individuals were placed into $50 \mathrm{~mL}$ of each dilution member of the test solution. The experiment was carried out with three parallels in $150 \mathrm{~mL}$ beakers. As a control, distilled water was applied with Hoagland's nutrient medium in similar proportion as in the triclosan containing samples. The beakers were covered with a translucent plastic film to avoid evaporation and concentration of the test suspension during the experiment. The assembled test systems (beakers) were incubated in a $21.5 \pm 1{ }^{\circ} \mathrm{C}$ thermostatic chamber for 7 days under the following light conditions: 16:8 h light: dark cycle (illumination: Juwel Aquarium, Day-Lite, $15 \mathrm{~W}, 438 \mathrm{~mm}$ lamp, 560 Lumen, $6500 \mathrm{~K}$ ).

On the seventh day the total frond number was determined in the test vessels, then the L. minor individuals were removed from the test solutions, then surface-dried on filter paper to constant weight. The dried biomass was placed into ground-necked test tubes containing $5 \mathrm{~mL}$ of $96 \%$ ethanol. After 24 hours the optical density of the samples was determined spectrophotometrically (Sanyo SP55 UV/VIS spectrophotometer) at 470, 649 and 664 $\mathrm{nm}$ wavelength values. The total chlorophyll content was determined based on the calculation described by FeketeKertész et al. [18].

The root length of each L. minor individual was measured with the help of a ruler before chlorophyll extraction.

\subsection{Simplified microcosm experiments}

Based on the results of the acute, single-species ecotoxicity tests, simplified small volume microcosm experiments were conducted with selected experimental setups.

Ten newborn $(<24 \mathrm{~h})$ D. magna individuals and five 10 -day-old $H$. incongruens individuals were placed into $150 \mathrm{~cm}^{3}$ glass beakers containing $100 \mathrm{~cm}^{3}$ test solutions. To reach the final concentration the $4 \mathrm{mg} / \mathrm{L}$ triclosan stock solution dissolved in natural surface water was diluted with the same natural surface water then mixed with D. magna growth medium in the ratio of 1:9. The beakers were covered with a translucent plastic film to avoid evaporation and concentration of the test solutions during the experiment. The assembled test systems (beakers) were incubated for 7 days under identical circumstances to the acute $D$. magna lethality and immobilization tests. The test organisms were fed at the beginning of the test and on the third day with $200 \mu \mathrm{L}$ Chlorella sorokiniana alga suspension $\left(10^{9}\right.$ cell $/ \mathrm{mL}$ concentration). During the 7 days of exposure time lethality and immobilization was registered every $24 \mathrm{~h}$. On the 7 th day the physico-chemical parameters $(\mathrm{pH}$, electric conductivity, dissolved oxygen concentration) of the exposure media were measured and beside the conventionally used lethality and immobilization, more sensitive, sublethal physiological and behavioral endpoints were determined, such as Daphnia magna heartbeat rate and feeding activity, and Heterocypris incongruens movement parameters (total distance and average velocity). The method of determination of these sublethal endpoints was as described in the case of acute test protocols. 


\subsection{Complex, multi-species microcosm experiments}

Based on the results of the acute, single-species ecotoxicity tests and the simplified, small volume microcosm experiments, complex multi-species microcosm experiments were conducted with selected experimental setups.

$100 \mathrm{~g}$ of artificial sediment (65\% quartz sand, $30 \%$ kaolinite powder, $3.9 \%$ ground peat, $1 \%$ cellulose powder and $0.1 \% \mathrm{CaCO}_{3}$ ) was sterilized in an autoclave with $500 \mathrm{~mL}$ tap water, then the solid phase was decanted and washed into a $2500 \mathrm{~cm}^{3}$ volume glass beaker (width: $12 \mathrm{~cm}$, height: $24 \mathrm{~cm}$ ) with $2000 \mathrm{~mL}$ sterilized surface water and the beakers were covered with a translucent plastic film. After complete sedimentation, aeration was started and adjusted to very gentle bubbling using mineral air diffuser stones. The microcosms were inoculated with $2 \mathrm{~mL}$ of $10^{5}$ cell $/ \mathrm{mL}$ concentration Chlorella sorokiniana and Scenedesmus subspicatus alga suspension mixture (1:1) and special illumination was applied (16:8 h light: dark cycle (illumination: Juwel Aquarium, Day-Lite, 15 W, 438 mm lamp, 560 Lumen, $6500 \mathrm{~K}$ ). After 3 days alga and dissolved oxygen concentration was checked to reach $10^{3}$ cell $/ \mathrm{mL}$ and $6 \mathrm{mg} / \mathrm{L}$ concentration, respectively. If these parameters met the criteria 16 newborn $(<24$ h) D. magna individuals and 6 10-day-old $H$. incongruens individuals were placed into each microcosm and were let to acclimatize $24 \mathrm{~h}$ before triclosan administration. To reach the final concentration the $4 \mathrm{mg} / \mathrm{L}$ triclosan stock solution dissolved in natural surface water were added to the microcosms by replacing the appropriate amount of microcosm water phase with the contaminant solution. This time point was considered as "day 0 " and the assembled microcosms were incubated for 21 days at $21.5 \pm 1{ }^{\circ} \mathrm{C}$. Each microcosm was reinoculated once a week with $2 \mathrm{~mL}$ of the same alga suspension used for the first inoculation. During the 21 days of exposure the number of test organisms (reproduction) was registered twice a week and the physico-chemical parameters ( $\mathrm{pH}$, electric conductivity, dissolved oxygen concentration) of the exposure media were also measured. On day 21 the following sublethal physiological and behavioral endpoints were determined: Daphnia magna heartbeat rate and feeding activity, Heterocypris incongruens movement parameters (total distance and average velocity), and Lemna minor total chlorophyll content and root length. The method of determination of these sublethal endpoints was as described in the case of acute test protocols.

\subsection{Data evaluation and statistical analysis}

In the case of each ecotoxicological endpoint inhibition percentage values $(\mathrm{H} \%)$ were calculated compared to control. One-way analysis of variance (ANOVA) was performed by STATISTICA $13^{\circledR}$ software identifying significant effects $(p<0.05)$. The homogeneity of variances was examined with Leven's test. In case of significance the Lowest Observed Effect Concentration (LOEC) values were determined using Dunnett's test $(\alpha=0.05)$.

\section{Results}

In a series of experiments the short- and midterm ecotoxicological effect of the antimicrobial agent, triclosan was investigated using variant test systems considering ecological complexity and environmental relevance. At each level of complexity the sensitivity of different ecotoxicological endpoints of the same test organism was compared based on the LOEC and inhibition percentage values. The response of the applied test organisms to triclosan administration in the three different complexity test systems was also compared.

\subsection{Acute, single-species ecotoxicity tests}

The effect of triclosan on D. magna lethality and normal physiology (heartbeat rate and feeding activity) was investigated applying $48 \mathrm{~h}$ exposure time. After the short exposure time $(48 \mathrm{~h})$ the heartbeat rate of the D. magna individuals showed alteration compared to control in case of all of the determined test endpoints with $\mathrm{LOEC}=4 \mu \mathrm{g} / \mathrm{L}$. The lowest concentration resulting significant inhibition of survival $(\mathrm{H} \%=30)$ and alteration of feeding activity was $1000 \mu \mathrm{g} / \mathrm{L}$. A strong stimulative effect (114\% compared to control) was experienced in the case of the surviving individuals exposed to $1000 \mu \mathrm{g} / \mathrm{L}$ concentration triclosan solution, which may be explained by an exaggerated physiological effect manifested in a struggling behavior like higher feeding rate (Fig. 1).

The conventionally used endpoints (lethality and immobilization) of $H$. incongruens did not prove to be sensitive enough to detect the adverse effect of triclosan in the $20-1000 \mu \mathrm{g} / \mathrm{L}$ concentration range. Significant effect was found only in the case of the most concentrated $2000 \mu \mathrm{g} / \mathrm{L}$ triclosan solution $(\mathrm{H} \%=67)$. In the case of $H$. incongruens no immobilization effect was detected at the tested concentrations even after $48 \mathrm{~h}$ of exposure time.

Two different ecotoxicological endpoints were applied in order to follow the inhibitory effect on Lemna minor growth. Significant inhibition was found only in the most 


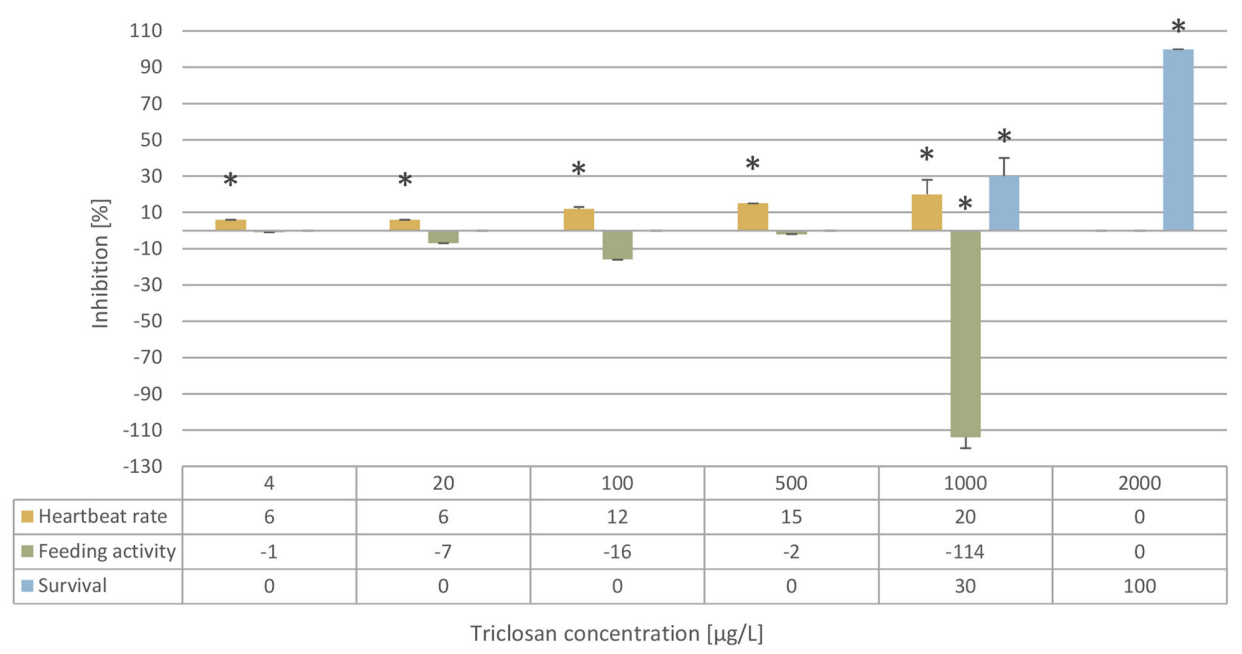

Fig. 1 The effect of triclosan on Daphnia magna after $48 \mathrm{~h}$ exposure time. Significant effect compared to control is marked by asterisk $\left({ }^{*}\right)$.

concentrated $(2000 \mu \mathrm{g} / \mathrm{L})$ triclosan treatment with the $\mathrm{H} \%$ of $18 \%$, however the total chlorophyll content indicated 44 and $66 \%$ inhibitory effect of the 1000 and $2000 \mu \mathrm{g} / \mathrm{L}$ concentration triclosan solutions, respectively (Fig. 2).

\subsection{Simplified, small volume microcosm experiments}

The ecotoxic effect of triclosan was investigated in an experimental series conducted in small volume microcosms exposing free-swimming D. magna and the benthic $H$. incongruens species to five different concentrations of triclosan in the range of $25.6-1000 \mu \mathrm{g} / \mathrm{L}$ with a 2.5 -fold dilution factor. Compared to the acute ecotoxicological tests, an additional exposure route was represented in this case via alga-adsorbed contaminant uptake. For this reason the test organisms were fed with algae suspension at the beginning and on the 3rd day of the experiments.

At the two highest triclosan concentrations (400 and $1000 \mu \mathrm{g} / \mathrm{L}$ ) none of the $D$. magna individuals survived and even in the $160 \mu \mathrm{g} / \mathrm{L}$ triclosan solution the survival rate was only $35 \%$, which meant significant inhibition compared to control. Heartbeat rate and feeding inhibition could be measured only at 25.6, 64 and $160 \mu \mathrm{g} / \mathrm{L}$ triclosane concentrations. In the $160 \mu \mathrm{g} / \mathrm{L}$ triclosan solution resulting significant lethality $(\mathrm{H} \%=65 \%)$, the feeding activity of the surviving animals was inhibited by $40 \%$ per individual. The extent of feeding inhibition was still $26 \%$ in the most diluted $25.6 \mu \mathrm{g} / \mathrm{L}$ triclosan solution. Significant inhibition of the heartbeat rate (12-20\%) was also detected in the $25.6-160 \mu \mathrm{g} / \mathrm{L}$ concentration range. In this context feeding inhibition proved to be the most sensitive ecotoxicological endpoint in determining the adverse effect of triclosan on newborn D. magna individuals raised in the test system for up to 7 days (Fig. 3).

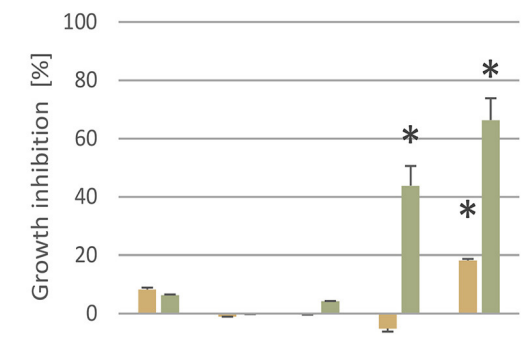

\begin{tabular}{|l|c|c|c|c|c|}
\cline { 2 - 6 } \multicolumn{1}{c|}{} & 20 & 100 & 500 & 1000 & 2000 \\
\hline E Frond number & 8 & -1 & 0 & -5 & 18 \\
\hline $\begin{array}{c}\text { - Total chlorophyll } \\
\text { content }\end{array}$ & 6 & 0 & 4 & 44 & 66 \\
\hline
\end{tabular}

Triclosan concentration $[\mu \mathrm{g} / \mathrm{L}]$

Fig. 2 The effect of triclosan on Lemna minor after $7 \mathrm{~d}$ exposure time. Significant effect compared to control is marked by asterisk $\left(^{*}\right)$.

While for the bottom-dwelling $H$. incongruens significant lethality was found only when exposed to $1000 \mu \mathrm{g} / \mathrm{L}$ triclosan solution, the behavioral endpoints characterizing its movement parameters (total distance and average speed) revealed significant alteration in behavior (43 and $35 \%$ inhibition, respectively) (Fig. 4).

\subsection{Complex, multi-species microcosm experiments}

Based on the results, of the small volume simplified microcosm studies, large volume multi-species microcosm test systems were assembled with the selected concentration of 20, 500 and $2000 \mu \mathrm{g} / \mathrm{L}$.

The dissolved oxygen concentration was above $5 \mathrm{mg} / \mathrm{L}$ in each microcosm during the 21 days exposure period, the $\mathrm{pH}$ ranged between $7.8-8.5$ and the electric conductivity ranged between $661-692 \mu \mathrm{S} / \mathrm{cm}$.

At 500 and $2000 \mu \mathrm{g} / \mathrm{L}$ triclosan concentrations there were no surviving D. magna individuals. Although 


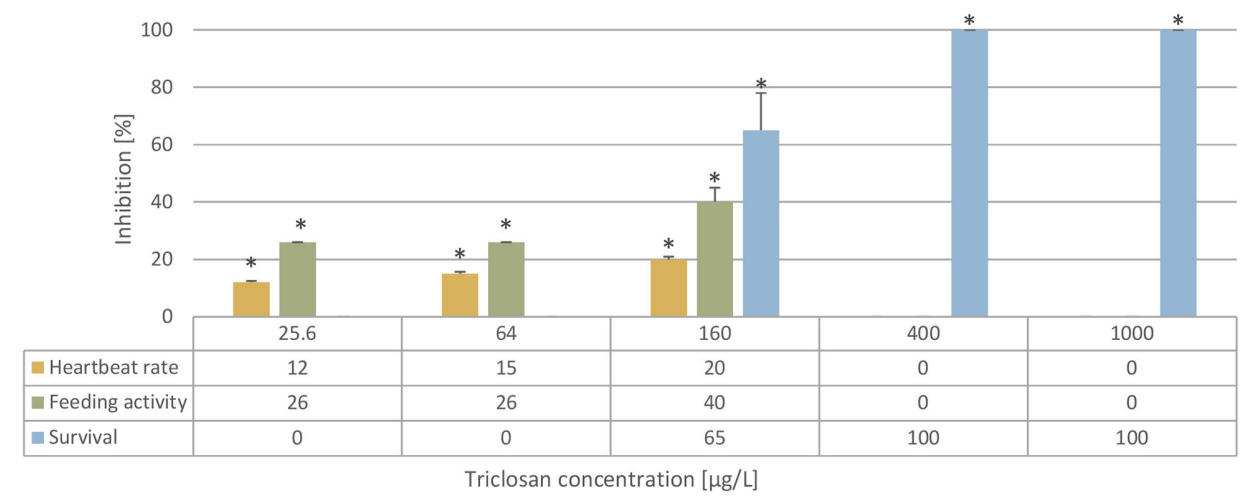

Fig. 3 The effect of triclosan on Daphnia magna after $7 \mathrm{~d}$ exposure time in the simplified small volume microcosm experiments. Significant effect compared to control is marked by asterisk (*).

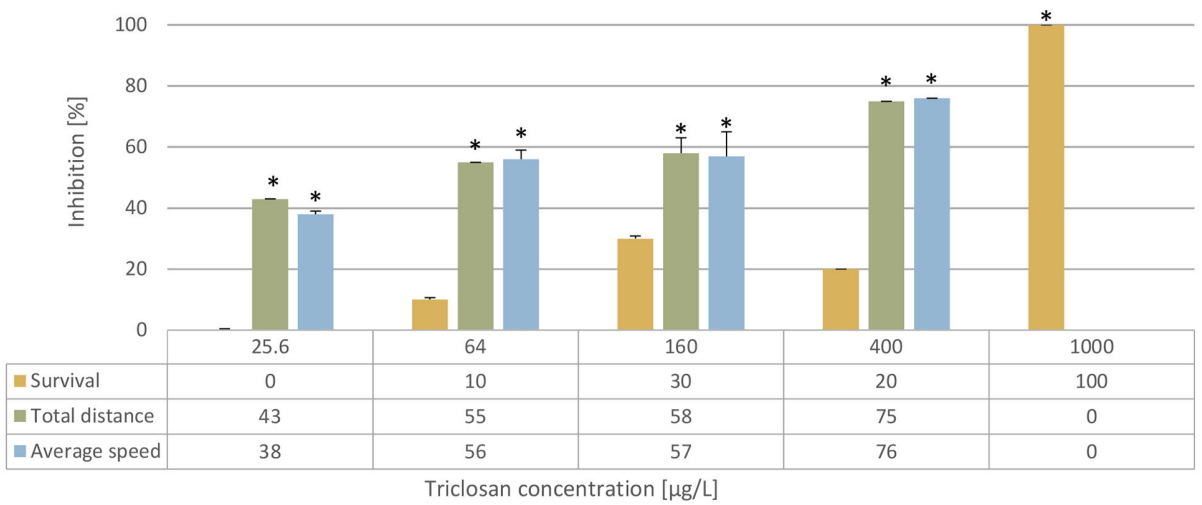

Fig. 4 The effect of triclosan on Heterocypris incongruens after $7 \mathrm{~d}$ exposure time in the simplified small volume microcosm experiments. Significant effect compared to control is marked by asterisk $(*)$.

triclosan at $20 \mu \mathrm{g} / \mathrm{L}$ concentration did not cause significant lethality or immobilization of D. magna it affected their feeding activity negatively (by $25 \%$ ) compared to control. In this case any modulation of the heartbeat rate was not detected, which may be explained by acclimatization of Daphnia individuals to the low concentration of triclosan during the 21 days exposure period (Fig. 5).

Presumably, a significant proportion of the administered triclosan and its metabolites were adsorbed to the artificial sediment applied in the test system, which might have exerted severe toxic effect on the bottom-dwelling H. incongruens. Triclosan at 500 and $2000 \mu \mathrm{g} / \mathrm{L}$ concentration inhibited reproduction by 32 and $89 \%$, respectively. However, at $20 \mu \mathrm{g} / \mathrm{L}$ concentration the reproduction inhibition was $22 \%$ (statistically non-significant). At $2000 \mu \mathrm{g} / \mathrm{L}$ concentration all $H$. incongruens individuals were immobilized and the inhibition of the average movement speed at 20 and $500 \mu \mathrm{g} / \mathrm{L}$ concentrations was 15 and $26 \%$, respectively, however these values were not significant statistically due to the high standard deviations (Fig. 6). Triclosan reduced significantly both the total chlorophyll content and root length of $L$. minor compared to the conventional frond number (Fig. 7). In this case the total chlorophyll content proved to be the most sensitive endpoint, the inhibition was $36 \%$ at $20 \mu \mathrm{g} / \mathrm{L}$ triclosan concentration.

\section{Discussion}

For comparative evaluation of the sensitivity of different test systems Lowest Observed Effect Concentration values (LOEC) were determined for all tested endpoints. The Lowest Observed Effect Concentration (LOEC) values are summarized in Table 2.

Comparing the survival rate of D. magna and H. incongruens it can be stated that LOEC values were lower after 7 days of exposure than in case of $48 \mathrm{~h}$ exposure time. The D. magna heartbeat rate test proved to be the most sensitive acute test (10-days-old test organism, $48 \mathrm{~h}$ exposure) when comparing the sublethal physiological and behavioral effects of the administered triclosan concentrations in the three test systems (different in complexity and 


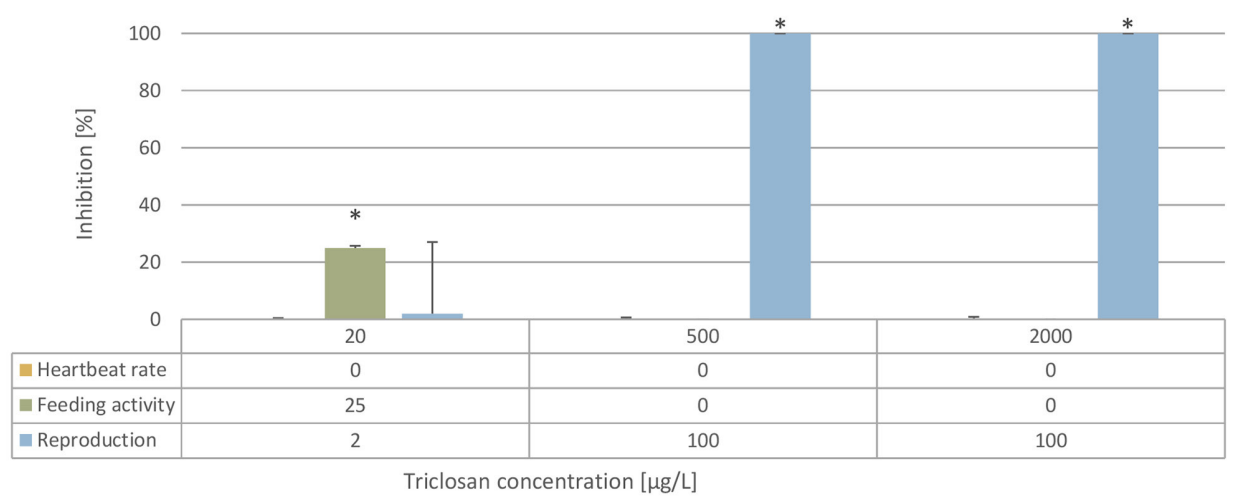

Fig. 5 The effect of triclosan on Daphnia magna after 21 d exposure time in the complex large volume microcosm experiments. Significant effect compared to control is marked by asterisk (*).

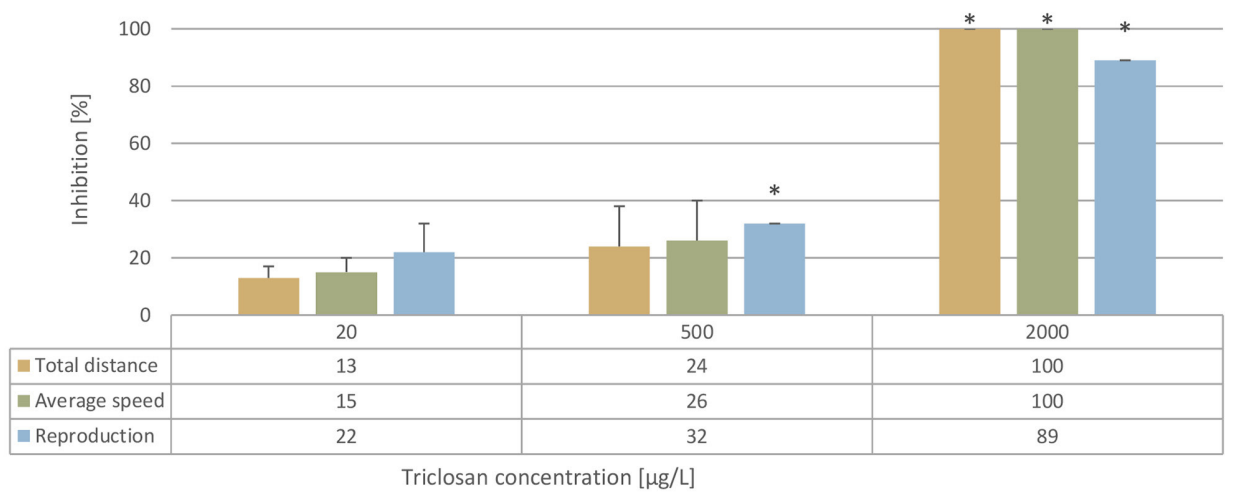

Fig. 6 The effect of triclosan on Heterocypris incongruens after $21 \mathrm{~d}$ exposure time in the complex large volume microcosm experiments. Significant effect compared to control is marked by asterisk $(*)$

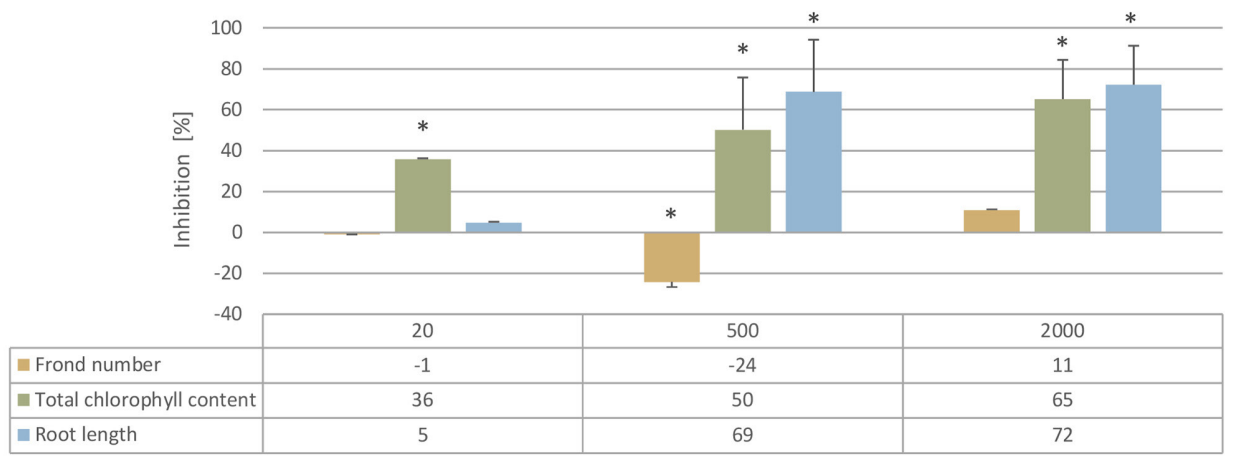

Triclosan concentration $[\mu \mathrm{g} / \mathrm{L}]$

Fig. 7 The effect of triclosan on Lemna minor after $21 \mathrm{~d}$ exposure time in the complex large volume microcosm experiments. Significant effect compared to control is marked by asterisk $(*)$.

exposure time). The heartbeat rate results of the simplified microcosm experiment also confirm the adverse effect of triclosan when the newborn Daphnids were growing in the presence of the contaminant for 7 days. Contrary to this the 21-days experiments did not show observable change in the heartbeat rate of the Daphnids exposed to
$20 \mu \mathrm{g} / \mathrm{L}$ triclosan from the very beginning of the experiment. Based on these results it can be concluded that low concentrations of triclosan may alter the heartbeat rate of Daphnids temporarily on the short- and midterm but on the long term the Daphnids are capable of acclimatizing to the presence of the contaminant. 
Table 2 Lowest Observed Effect Concentrations determined in the three different test system in terms of ecological complexity and exposure time

\begin{tabular}{|c|c|c|c|c|}
\hline \multicolumn{5}{|c|}{$\mathrm{LOEC}[\mu \mathrm{g} / \mathrm{L}]$} \\
\hline Test organism & Ecotoxicity endpoint & Single-species acute tests & $\begin{array}{l}\text { Two-species simplified } \\
\text { microcosms }\end{array}$ & $\begin{array}{c}\text { Multi-species complex } \\
\text { microcosms }\end{array}$ \\
\hline \multirow{5}{*}{ Daphnia magna } & Survival & 1000 & 160 & - \\
\hline & Immobilization & 1000 & $160-400$ & $20-500$ \\
\hline & Reproduction inhibition & - & - & 500 \\
\hline & Heartbeat rate & 4 & 25.6 & $20-500$ \\
\hline & Feeding activity* & 1000 & 25.6 & 20 \\
\hline \multirow{5}{*}{ Heterocypris incongruens } & Survival & 2000 & 1000 & - \\
\hline & Immobilization & $>2000$ & $400-1000$ & 2000 \\
\hline & Reproduction inhibition & - & - & 500 \\
\hline & Total distance & - & 25.6 & 2000 \\
\hline & Average speed & - & 25.6 & 2000 \\
\hline \multirow{3}{*}{ Lemna minor } & Frond number & 2000 & - & 2000 \\
\hline & Total chlorophyll content & 1000 & - & 20 \\
\hline & Root length & - & - & 500 \\
\hline
\end{tabular}

* Calculated per individual

- Not determined

Regarding the feeding activity of D. magna in the different test systems major differences were also found. In the acute test feeding activity was significantly stimulated only at the highest concentration $(1000 \mu \mathrm{g} / \mathrm{L})$, while when exposed to low triclosan concentrations for 7 or 21 days feeding activity was significantly inhibited depending on the triclosan concentration. A possible explanation of this phenomenon can be that Daphnids on the short term respond to the high triclosan concentrations accelerating their metabolic functions struggling against environmental stress or the bioaccumulation of triclosan during longer periods may induce metabolic pathways responsible for detoxification, resulting in the production of triclosan intermediate compounds (e.g. by biological methylation), that are more toxic than the parent compound and have weak estrogenic activity [20]. In the $160 \mu \mathrm{g} / \mathrm{L}$ triclosan solution of the simplified microcosms in addition to the significant inhibition of survival, heartbeat rate and feeding activity, the size of the surviving Daphnids was visibly smaller compared to control after 7 days of exposure, therefore in future experiments we recommend body size as a possible measurement endpoint.

Thyroid hormones play important role in growth, development and metabolism of vertebrates. $\mathrm{Wu}$ et al. [21] identified thyroid hormone receptor orthologues in Daphnia pulex, thus the experienced modulation in body size and the physiological endpoints may be explained by the proven thyroid hormone action [22] of triclosan and its metabolite, triclocarban. Peng et al. [23] investigated the toxic effects of different concentrations of triclosan $(1-128 \mu \mathrm{g} / \mathrm{L})$ on $D$. magna by acute $(48 \mathrm{~h})$ and chronic (21-day) toxicity tests. The response of antioxidase system and Phase I metabolism process were investigated by measuring a series of biomarkers including glutathione S-transferase (GST), catalase (CAT), superoxide dismutase (SOD), malondialdehyde (MDA), 7-ethoxyresorufin O-deethylase (EROD), Erythromycin N-demethylase (ERND) and Aminopyrine N-demethylase (APND). They found that the GST and CAT activities showed no significant increase in all treatments and SOD, MDA and APND were sensitive to triclosan, thus the possible mode of action behind the inhibition of the physiological endpoints in our study can be the above described modulation of the antioxidase system and Phase I metabolism process investigated by Peng et al. [23]. In the chronic test, they found that the total number of neonates per female, body length, total number of molting per adult and the intrinsic rate of natural increase of $D$. magna decreased between the concentrations range $64-128 \mu \mathrm{g} / \mathrm{L}$.

Li et al. [24] investigated the $\mathrm{pH}$-dependent toxicity of triclosan to five aquatic organisms amongst them D. magna, Photobacterium phosphoreum, Danio rerio(,) and Limnodrilus hoffmeisteri. They found that generally, triclosan was more toxic to the four aquatic organisms in acidic medium. During our experiments the measured $\mathrm{pH}$ was in the range of 7.8-8.5, therefore it can be assumed that the extent of the toxic effect would be greater under acidic circumstances. 
According to our knowledge currently no data are available on the toxic effect of triclosan on $H$. incongruens, however due to the high sorption-coefficient of triclosan, the sediment-bounded fraction of triclosan is a remarkable exposure route in terms of risk assessment of triclosan in the aquatic ecosystems. With longer exposure periods, the occurrence of lethal effect became more likely in case of $H$. incongruens. Our result proved that $25.6 \mu \mathrm{g} / \mathrm{L}$ triclosan significantly alters the movement parameters of the $H$. incongruens individuals, but further experiments are necessary in order to investigate the possible mode of action behind this effect.

Orvos et al. [25] reported $\mathrm{EC}_{25(7 \mathrm{~d})}>62.5 \mu \mathrm{g} / \mathrm{L}$ for Lemna gibba and explained the lack of sensitivity of Lemna sp. by the rapid metabolism of triclosan or thanks to reduced uptake due to a barrier. Küster et al. [26] determined a $\mathrm{EC}_{50(24 \mathrm{~h})}=1690 \mu \mathrm{g} / \mathrm{L}$ for the effect of triclosan on $L$. minor with the chlorophyll fluorescence method and they found this method less sensitive compared to long-term bioassays, which might be due to physicochemical substance properties such as lipophilicity. Contrary to this LOEC $=20 \mu \mathrm{g} / \mathrm{L}$ in our 21-day-long microcosm experiment was determined when triclosan decreased the chlorophyll content of L. minor significantly by $36 \%$, which draws the attention to the potential long-term adverse effect of the non-PSII herbicide triclosan at low concentrations on higher trophic level photosynthetic plants in the aquatic ecosystem.

Liebig et al. [27] studied the effect of the pesticides parathion-methyl and prometryn on phototrophic flagellates (Cryptomonas sp.) and predatory ciliates (Urotricha furcata) applying an aquatic indoor microcosm. They also found significant differences between the results of single-species and multi-species microcosm experiments such as for ciliates the NOEC decreased by factor 145 in the multi-species test compared to the NOEC of $2.2 \mathrm{mg} / \mathrm{L}$ in the single-species test when exposed to prometryn.

Our results of these preliminary microcosm experiments with three different triclosan concentrations clearly demonstrated the importance of ecotoxicological assessment of triclosan in complex aquatic microcosm test systems, therefore as a next step more dilution members will be applied at a wider concentration range.

\section{Conclusion}

Based on the results of acute single-species, simplified microcosm experiments and complex multi-species microcosm experiments all physiological and behavioral endpoints indicated sensitively the adverse effect of triclosan in the concentration range of 4-25.6 $\mu \mathrm{g} / \mathrm{L}$. D. magna sensitivity to triclosan increased with the increase of complexity and environmental relevance in case of all applied ecotoxicological endpoints except the heartbeat rate. The L. minor chlorophyll content endpoint supported this trend as well. Our results draw the attention to the advantages of using complex, environmentally more relevant test systems for the environmental risk assessment of triclosan, considering the different results in the case of the three test systems different in complexity. The difference between the results of the single-species acute tests and the complex microcosm tests also support the theory that it is hard to extrapolate from the results of single-species acute tests to real environmental effects of triclosan on the long term. According to our results, exposure time and different combinations of exposure routes due to varying ecological complexity of the assembled test systems are the most decisive parameters in terms of triclosan ecotoxicity and endpoint sensitivity.

Based on the applied complex ecotoxicological methodology with three trophic levels including responses based on physiological and behavioral ecotoxicity endpoints we provided a more realistic assessment of the impacts and exposure of triclosan of aquatic organisms in water bodies. This work supplements the presently available data on the toxicity of triclosan as well as allows a deeper understanding of additional and hidden effects of triclosan on aquatic life thorough various exposure routes. The results obtained by this complex research may support risk assessment of triclosan in freshwater environment aiding determination of the Predicted No Effect Concentration (PNEC) values and serving as a tool for modelling the environmental fate of bioactive contaminants in the ecosystem.

\section{Acknowledgements}

This work was supported by the Higher Education Excellence Program of the Ministry of Human Capacities in the frame of Biotechnology research area of Budapest University of Technology and Economics (BME FIKP$\mathrm{BIO})$. We are grateful to Emese Vaszita for her contribution to language editing of the manuscript. 


\section{References}

[1] Popa Ungureanu, C., Favier, L., Bahrim, G. "Screening of soil bacteria as potential agents for drugs biodegradation: a case study with clofibric acid", Journal of Chemical Technology and Biotechnology, 91(6), pp. 1646-1653, 2016.

https://doi.org/10.1002/jctb.4935

[2] Favier, L., Simion, A. I., Rusu, L., Pacala, M. L., Grigoras, C., Bouzaza, A. "Removal of an organic refractory compound by photocatalysis in batch reactor-kinetic studies", Environmental Engineering and Management Journal, 14(6), pp. 1327-1338, 2015. https://doi.org/10.30638/eemj.2015.144

[3] Dhillon, G. S., Kaur, S., Pulicharla, R., Brar, S. K., Cledón, M., Verma, M., Surampalli, R. Y. "Triclosan: Current Status, Occurrence, Environmental Risks and Bioaccumulation Potential", International Journal of Environmental Research and Public Health 12(5), pp. 5657-5684, 2015.

https://doi.org/10.3390/ijerph120505657

[4] Bedoux, G., Roig, B., Thomas, O., Dupont, V., Le Bot, B. "Occurrence and toxicity of antimicrobial triclosan and by-products in the environment", Environmental Science and Pollution Research 19(4), pp. 1044-1065, 2012.

https://doi.org/10.1007/s11356-011-0632-z

[5] Dye, C., Schlabach, M., Green, J., Remberger, M., Kaj, L., PalmCousins, A., Brorström-Lundén, E. "Bronopol, Resorcinol, m-Cresol and Triclosan in the Nordic Environment", Nordic Council of Ministers, Copenhagen, Denmark, TemaNord 2007:585, 2007, [online] Available at: http://www.nordicscreening. org/index.php [Accessed: 1 July 2018]

[6] Chalew, T. E. A., Halden, R. U. "Environmental Exposure of Aquatic and Terrestrial Biota to Triclosan and Triclocarban", Journal of the American Water Resources Association, 45(1), pp. 4-13, 2009. https://doi.org/10.1111/j.1752-1688.2008.00284.x

[7] Reiss, R., Lewis, G., Griffin, J. "An ecological risk assessment for triclosan in the terrestrial environment", Environmental Toxicology and Chemistry, 28(7), pp. 1546-1556, 2009. https://doi.org/10.1897/08-250.1

[8] Kinney, C. A., Furlong, E. T., Kolpin, D. W., Burkhardt, M. R., Zaugg, S. D., Werner, S. L., Bossio, J. P., Benotti, M. J. "Bioaccumulation of Pharmaceuticals and Other Anthropogenic Waste Indicators in Earthworms from Agricultural Soil Amended with Biosolid or Swine Manure", Environmental Science \& Technology, 42(6), pp. 1863-1870, 2008. https://doi.org/10.1021/es702304c

[9] Peng, X., Yu, Y., Tang, C., Tan, J., Huang, Q., Wang, Z. "Occurrence of steroid estrogens, endocrine-disrupting phenols and acid pharmaceutical residues in urban riverine water of the Pearl River Delta, South China", Science of the Total Environment, 397(1-3), pp. 158-166, 2008.

https://doi.org/10.1016/j.scitotenv.2008.02.059

[10] Zhao, J.-L., Ying, G.-G., Liu, Y.-S., Chen, F., Yang, J.-F., Wang, L. "Occurrence and risks of triclosan and triclocarban in the Pearl River system, South China: From source to the receiving environment", Journal of Hazardous Materials, 179(1-3), pp. 215-222, 2010.

https://doi.org/10.1016/j.jhazmat.2010.02.082
[11] Scientific Committee on Consumer Safety (SCCS). "Opinion on: Triclosan Antimicrobial, Resistance", Directorate-General for Health \& Consumersrs (European Commission), Brussels, Belgium, SCCP/1251/09, 2010.

[12] Schweizer, H. P. "Triclosan: a widely used biocide and its link to antibiotics", FEMS Microbiology Letters, 202(1), pp. 1-7, 2001. https://doi.org/10.1111/j.1574-6968.2001.tb10772.x

[13] Adolfsson-Erici, M., Pettersson, M., Parkkonen, J., Sturve, J. "Triclosan, a commonly used bactericide found in human milk and in the aquatic environment in Sweden", Chemosphere, 46(9-10), pp. 1485-1489, 2002. https://doi.org/10.1016/S0045-6535(01)00255-7

[14] Latch, D. E., Packer, J. L., Arnold, W. A., McNeill, K. "Photochemical conversion of triclosan to 2,8-dichlorodibenzo-p-dioxin in aqueous solution", Journal of Photochemistry and Photobiology A: Chemistry, 158(1), pp. 63-66, 2003. https://doi.org/10.1016/S1010-6030(03)00103-5

[15] De Laender, F., De Schamphelaere, K. A. C., Vanrolleghem, P. A., Janssen, C. R. "Do we have to incorporate ecological interactions in the sensitivity assessment of ecosystems? An examination of a theoretical assumption underlying species sensitivity distribution models", Environment International, 34(3), pp. 390-396, 2008. https://doi.org/10.1016/j.envint.2007.09.006

[16] Boxall, A., Brown, C, Barrett, K. "Higher tier laboratory aquatic toxicity testing", Cranfield Centre for EcoChemistry, Derby, United Kingdom, research report No. JF 4317E for DETR, 70p. 2001.

[17] Organisation for Economic Co-operation and Development: OECD "Test No. 202: Daphnia sp. Acute Immobilisation Test", OECD Publishing, Paris, France, 2004.

[18] Fekete-Kertész, I., Kunglné-Nagy, Zs., Gruiz, K., Magyar, Á., Farkas, É., Molnár, M. "Assessing Toxicity of Organic Aquatic Micropollutants Based on the Total Chlorophyll Content of Lemna minor as a Sensitive Endpoint", Periodica Polytechnica Chemical Engineering, 59(4), pp. 262-271, 2015. https://doi.org/10.3311/PPch.8077

[19] Kamaya, M., Sonamoto, M., Nagashima, K., Ginatullina, E. N. "A Simple Bioassay Using Fluorescent Microbeads and Daphnia magna", Journal of Environmental Science and Engineering, 5(12), pp. 1613-1616, 2011.

[20] Huang, H., Du, G., Zhang, W., Hu, J., Wu, D., Song, L., Xia, Y., Wang, X. "The in Vitro estrogenic activities of triclosan and triclocarban", Journal of Applied Toxicology, 34(9), pp. 1060-1067, 2014. https://doi.org/10.1002/jat.3012

[21] Wu, W., Niles, E. G., LoVerde, P. T. "Thyroid hormone receptor orthologues from invertebrate species with emphasis on Schistosoma mansoni", BMC Evolutionary Biology, 7(150), 2007. https://doi.org/10.1186/1471-2148-7-150

[22] Hinther, A., Bromba, C. M., Wulff, J. E., Helbing, C. C. "Effects of Triclocarban, Triclosan, and Methyl Triclosan on Thyroid Hormone Action and Stress in Frog and Mammalian Culture Systems", Environmental Science \& Technology, 45(12), pp. 5395-5402, 2011. https://oi.org/10.1021/es1041942 
[23] Peng, Y., Luo, Y., Nie, X.-P., Liao, W., Yang, Y.-F., Ying, G.-G. "Toxic effects of Triclosan on the detoxification system and breeding of Daphnia magna", Ecotoxicology, 22(9), pp. 1384-1394, 2013. https://doi.org/10.1007/s10646-013-1124-3

[24] Li, C., Qu, R., Chen, J., Zhang, S., Allam, A. A., Ajarem, J, Wang, Z. "The pH-dependent toxicity of triclosan to five aquatic organisms (Daphnia magna, Photobacterium phosphoreum, Danio rerio, Limnodrilus hoffmeisteri, and Carassius auratus)", Environmental Science and Pollution Research, 25(10), pp. 96369646, 2018.

https://doi.org/10.1007/s11356-018-1284-z

[25] Orvos, D. R., Versteeg, D. J., Inauen, J., Capdevielle, M., Rothenstein, A., Cunningham, V. "Aquatic toxicity of triclosan", Environmental Toxicology and Chemistry, 21(7), pp. 1338-1349, 2002. https://doi.org/10.1002/etc.5620210703
[26] Küster, A., Pohl, K., Altenburger, R. "A fluorescence-based bioassay for aquatic macrophytes and its suitability for effect analysis of non-photosystem II inhibitors", Environmental Science and Pollution Research, 14(6), pp. 377-383, 2007. https://doi.org/10.1065/espr2007.04.410

[27] Liebig, M., Schmidt, G., Bontje, D., Kooi, B. W., Streck, G., Traunspurger, W., Knacker, T. "Direct and indirect effects of pollutants on algae and algivorous ciliates in an aquatic indoor microcosm", Aquatic Toxicology, 88(2), pp. 102-110, 2008. https://doi.org/10.1016/j.aquatox.2008.03.010 